Trajectories of internalising and externalising symptoms and inflammation in the general child population

Eirini Flouri* PhD; Glyn Lewis ${ }^{* *} \mathrm{PhD}$, Marta Francesconi* $\mathrm{PhD}$

*Department of Psychology and Human Development, UCL Institute of Education, University College London, UK

** Division of Psychiatry, Faculty of Brain Sciences, University College London, UK

Correspondence: Eirini Flouri, Department of Psychology and Human Development, UCL Institute of Education, 25 Woburn Square, London WC1H 0AA, UK, e.flouri@ucl.ac.uk, tel:+44(0)2076126289 


\title{
Trajectories of internalising and externalising symptoms and inflammation in the general child population
}

\begin{abstract}
Background Elevations in inflammatory marker levels have been shown to precede
\end{abstract} internalising and externalising problems in the general child population. One study has found the reverse, that elevations in inflammatory marker levels in childhood follow internalising and externalising problems. However, the authors did not explore the role of the course of these problems in childhood or adjust for a number of potential confounders including psychosocial stressors and prenatal and perinatal exposures. Aims To investigate the association in childhood between the growth of internalising and externalising symptoms and levels of inflammatory markers, while accounting for potential confounders. Methods Using data from the Avon Longitudinal Study of Parents and Children, we tested the association between the trajectories of internalising (emotional and social) and externalising (hyperactivity and conduct) problems, at ages 4, 6, 8 and 9 years, and levels of C-reactive protein (CRP) and interleukin $6(\mathrm{IL}-6)$ at age 9 years. We analysed data $(\mathrm{n}=4,525)$ using latent growth curve modelling and linear regression. Results Children who had increasing levels of internalising symptoms over childhood were more likely to have higher levels of CRP and IL-6 at 9 years of age, even after adjustment for confounders. A one-unit increase in the rate of annual change of internalising symptoms was related to an increase of $12 \%$ and $8 \%$ in the level of CRP and IL-6, respectively. However, there was no evidence for an association between externalising symptoms and either inflammatory marker. Conclusions This study is the first step towards identifying a robust pathway, via increases in emotional and social difficulties, to elevated inflammation in healthy children. This association, if causal, suggests that effective interventions for children experiencing chronic emotional and 
social difficulties could also have physical health benefits. Keywords: internalising symptoms, externalising symptoms, ALSPAC, inflammation, IL-6, CRP 


\section{Introduction}

Elevated plasma levels of inflammatory markers are known to be associated with worse physical and mental health outcomes (Collaboration 2010, Kiecolt-Glaser et al., 2015). Higher inflammatory marker levels have been linked with atherosclerosis and risk of coronary heart disease as well as several psychiatric diseases such as depression and psychosis (Collaboration 2010, Danesh et al., 2008, Khandaker et al., 2014, Pillinger et al., 2019). Inflammation has an effect on brain morphology and connectivity which may contribute to its link with impairments in mood, cognition and perception, in turn associated with mental health problems (Marsland et al., 2015). Nonetheless, there is also compelling evidence that the relationship may be bidirectional, at least with depression, with depressive symptoms prompting immune dysregulation, in turn leading to maladaptive immune and endocrine changes (Copeland et al., 2012, de Baumont et al., 2019, Frolkis et al., 2019, Glaser et al., 2003, Stewart et al., 2009).

Understanding the variation in levels of inflammation in healthy individuals, especially children, has attracted much interest recently. One hypothesis is that internalising and externalising symptoms in childhood (Goodman et al., 2010) (Rutter et al., 2006) (Fergusson et al., 2005, Reef et al., 2011) could lead to increases in inflammation later in childhood and adulthood (Appleton et al., 2011, Slopen et al., 2013a). This is plausible in view of the role of internalising and externalising symptoms in the activation of the sympathetic nervous system (Matthys et al., 2013, Obradović and Boyce 2012), in turn stimulating inflammation (Cole et al., 2015), but also in view of the complex bidirectional association between self-regulation and such problems in children. Poor self-regulation, related to emotional and behavioural problems in children, can lead to poor health habits and cause stress generation behaviours, both of which lead to greater exposure to stress and disease, in turn associated with inflammation (Shields et al., 2017). 
With most studies to date assuming a pathway from inflammation to illness, including mental illness, exploring the reverse direction of the association between inflammation and mental health problems in children is unusual. However, a recent study using data from the Bucharest Early Intervention Project, a longitudinal randomised trial of high-quality foster care as an alternative to institutional care, showed that externalising symptom trajectories across ages 8-16 years were related to elevated inflammation [C-reactive protein (CRP)] at age 16 years, although only in those who received care as usual within institution. In the same group of children, higher internalising behaviours at age 8 , but not the rate of change in these behaviours, also predicted higher levels of CRP at age 16 (Tang et al., 2019).

The one general-population longitudinal study we are aware of that explores this question in children found that internalising and externalising problems at age 8 years were associated with higher levels of interleukin 6 (IL-6) and CRP about a year later (Slopen et al., 2013a). Nonetheless, that study measured internalising and externalising problems at one point in time. For a large minority of children however change rather than stability in emotional and behavioural symptoms is the norm (Flouri et al., 2018). Such within-individual change, in turn, can be relevant for important outcomes later on (Brook et al., 2013, Dekker et al., 2007, Flouri et al., 2018). Taken together these findings suggest that measuring emotional and behavioural problems in children at one point in time may underestimate the degree of both level, and importantly, chronicity of internalising and externalising symptoms. Underestimating chronicity may be especially problematic: with respect to inflammation, more chronic psychiatric conditions seem to have a more significant impact on inflammatory processes (Anisman et al., 1999, Wolkowitz et al., 2011). Furthermore, although Slopen et al.’s (2013a) study controlled for body mass index (BMI), gender, ethnicity and socioeconomic status (SES), it did not consider other important confounders, including childhood psychosocial stressors (Hammen 2006, Slopen et al., 2013b, Copeland et al., 2014, 
Danese et al., 2007), or foetal programming (Slopen et al., 2013b, Slopen et al., 2015,

Gluckman et al., 2008). We carried out this study to fill these gaps. Using data from the Avon Longitudinal Study of Parents and Children (ALSPAC), we investigate the association in childhood between the growth of internalising and externalising symptoms across ages 4 to 9 years and levels of IL-6 and CRP at age 9 years, while considering a range of potential confounders including both psychosocial stressors and foetal programming.

\section{Methods}

\section{Study design and participants}

The Avon Longitudinal Study of Parents and Children (ALSPAC) is an ongoing birth cohort study that recruited 14,541 pregnant women resident in Avon, UK, with expected delivery dates from April $1^{\text {st }} 1991$ to December $31^{\text {st }} 1992$. Additional children were recruited using the original enrolment definition from the participating children's age 7 years onwards, increasing the number to 15,445 to date (Fraser et al., 2013). ALSPAC was designed to explore how environmental and physical factors, assessed during and after pregnancy, might affect the development, health, or behaviour of the child (Boyd et al., 2013). From the first trimester of pregnancy parents completed postal questionnaires about themselves and the study child's health and development. Children were invited to attend annual assessment clinics including face-to-face interviews and psychological and physical tests from age 7 years onward (http://www.bristol.ac.uk/alspac/researchers/our-data/ for information about all the data that is available). Ethical approval for the study was received from the ALSPAC Ethics and Law Committee and the local research ethics committees (for full details on the ethics committee/institutional review board(s) that approved aspects of the study please see http://www.bristol.ac.uk/alspac/researchers/research-ethics/). All participants provided written informed consent and there was no financial compensation (details at www.alspac.bris.ac.uk). Our analytic sample included children (singletons and first-born 
twins or triplets) who had data on inflammation at age 9 years (measured in ALSPAC with CRP and IL-6) and who did not report an infection at the time of blood collection or during the preceding week $(n=4,525)]$.

\section{Measures}

Inflammation, age 9 years

Blood samples were collected from participants during the clinic visit at 9 years. IL-6 $(\mathrm{pg} / \mathrm{mL})$ was measured by enzyme-linked immunosorbent assay (R\&D Systems) and highsensitivity CRP (mg/L) was measured by automated particle-enhanced immunoturbidimetric assay (Roche). All inter-assay coefficients of variation were less than 5\%. In the full ALSPAC sample, IL-6 values ranged from 0.007 to $20.051 \mathrm{pg} / \mathrm{mL}$, while CRP values ranged from 0.01 to $67.44 \mathrm{mg} / \mathrm{L}$ (for 60 children CRP values were over $10 \mathrm{mg} / \mathrm{L}$ ). Both CRP and IL6 were $\log$-transformed for the analyses.

Internalising and externalising symptoms, ages 4-9 years

These were assessed using the mother-rated Strengths and Difficulties Questionnaire (SDQ) at ages 4, 6, 8 and 9 years. The SDQ is a valid and reliable tool for measuring such problems in children (Goodman 2001). It consists of 20 'difficulties' items related to behaviour (in the past 6 months), with each item scored on a 3 -point scale $(0=$ 'not true', $1=$ 'somewhat true', and 2 = 'certainly true'). Items can be summed to form four scales (emotional, conduct, hyperactivity, and peer problems) or two (internalising symptoms, the sum of the scores on the emotional and peer problems items, and externalising symptoms, the sum of the scores on the conduct and hyperactivity problems items), which we used for this analysis (Goodman et al., 2010).

\section{Covariates}

We included a number of covariates known to be associated with inflammation and internalising and externalising problems, including: gender, ethnicity (white, non-white), 
parental SES (which we approximated by maternal education), BMI (measured during the clinic visit at age 9 years), maternal alcohol consumption during pregnancy (yes, no), maternal cigarette smoking during pregnancy (yes, no), gestational diabetes or hypertension (yes, no), maternal infections during pregnancy (yes, no), preterm birth ( $<37$ weeks), low birth weight (below 2,500 grams), prenatal adverse life events, childhood adverse life events, and peer victimisation. Prenatal events (Supplementary Table S1) were measured in ALSPAC using a 41-item life events inventory (Barnett et al., 1983, Brown et al., 1973, Brown et al., 2009, Honnor et al., 1994), completed by the mother, at two time-points: at 18 weeks gestation (covering events since the beginning of the pregnancy) and at 8 weeks postpartum (covering events since 18 weeks gestation). At each time-point, a score of 0 was assigned if the event did not occur and a score of 1 if it did. We then calculated a total score capturing whether each of the 41 events ever occurred at any of the two time-points.

Childhood events were measured using a 14-item upsetting events checklist (Barnett et al., 1983, Brown et al., 1973, Brown et al., 2009, Honnor et al., 1994) (Supplementary Table S1), also completed by the mother, at the following time-points: 18 months (covering events since the child was 6 months), 30 months (events since the child was 18 months), 42 months (since the child was 30 months), 57 months (since the child was 42 months), 69 months (since the child was 57 months), 81 months (since the child was 69 months), and 103 months (since the child was 81 months). At each time-point we calculated the number of events experienced. Peer victimisation in childhood was measured with a modified version of the Bullying and Friendship Interview Schedule at age 8 years (Woods and Wolke 2003). Children were asked questions about their experiences as victims and perpetrators of both overt and relational bullying. We used the information about both types of bullying to compute a bullying status variable (not involved in bullying; bully-victim; pure victim; pure bully) (Winsper et al., 2012). 


\section{Statistical analysis}

All analyses were performed in STATA 15.0 (Stata Corporation, College Station, TX, 1997). We used latent growth curve modelling (LGCM) (Jung and Wickrama 2008) in order to identify trajectories of children's internalising and externalising symptoms from 4 to 9 years, and trajectories of children's adverse life events from 18 to 103 months. The individual predicted values of the intercept (set at baseline) and the slope (rate of annual change) were then used in the model. Using the predict command in STATA we generated predictions for the out-of-sample cases, i.e., the cases that were not used in the original estimation. This command uses the maximum likelihood with missing values (MLMV) estimation for those who had data on at least one time-point and single imputation for those missing information on all time-points (207 children in our sample). In this way we were able to estimate the intercepts and slopes of childhood events and internalising and externalising symptoms in our whole analytic sample $(n=4,525)$. The individual predicted values of the intercepts and the slopes were then saved and tested as predictors of inflammation at age 9 in linear regression models, fitted separately for log transformed CRP and IL-6 levels. We fitted three sets of models. Model 1 included only the intercepts and slopes of internalising and externalising problems. Model 2 added children's adverse life events, gender, ethnicity, BMI and SES. Model 3 additionally adjusted for the confounders measured at the prenatal period (alcohol consumption, cigarette smoking, gestational diabetes or hypertension, maternal infections, adverse life events), alongside preterm birth and low birth weight. In a sensitivity analysis, we refitted Model 3 using data on children without any psychiatric disorders $(n=4,384)$ (results available in the Supplementary Material).

Both outcomes (CRP and IL-6) and exposures (internalising and externalising symptoms) therefore had complete data. Missingness among the confounders ranged from $0.08 \%$ (gender) to $41.41 \%$ (preterm birth). Missing data on the confounders were then 
imputed (20 imputed datasets) using multiple imputation by chained equations (MICE). We assumed that missingness was dependent on observed data (missing at random). To predict missing data, we used all variables selected for analysis models. We imputed up to the analytic sample, and fitted all models in both the complete cases sample and the imputed cases sample (Table 2).

\section{Results}

Descriptive analyses

Table 1 shows the descriptive characteristics of our sample, including means and proportions for the exposures, outcomes and covariates. As expected, externalising scores were consistently higher than internalising scores and showed less stability, decreasing gradually with age from the preschool period onwards. Figure 1 shows the average internalising and externalising symptom trajectories across our study period. The number of adverse life events across the study period was relatively stable. The most common events in childhood and pregnancy were, respectively, separation from the father and income reduction (not shown). Correlations between the study variables were low to moderate, as expected (Supplementary Table S2).

\section{IL-6 models}

In Model 1, the slope of internalising symptoms was associated with IL-6. We had statistical evidence that supported an association between them $(b=.08, \mathrm{SE}=.04, \mathrm{p}=.045)$ even after adjustment for the childhood confounders (adverse life events, BMI, gender, SES, ethnicity; Model 2). The sizes of the regression coefficient and its standard error were unchanged ( $\mathrm{p}=.062)$ after full adjustment (Model 3). Thus, interpreting the exponentiated regression coefficient (Supplementary Table S3 for all exponentiated coefficients from all models), a one-unit increase in the slope was related to an $8 \%$ increase in the level of IL-6. The only significant confounders in Model 3 remained gender and BMI. There was no 
evidence that the slope or the intercept of externalising symptoms were associated with IL-6 level (Table 2).

\section{CRP models}

Model 1 showed that both the slope of internalising symptoms and that of externalising symptoms were associated - positively and negatively, respectively - with CRP. However, after partial (Model 2) and full (Model 3) adjustment for covariates only the slope of internalising symptoms maintained its association with CRP (Table 2). A one-unit increase in the slope was related to a $12 \%$ increase in the level of CRP (Supplementary Table S3 for all exponentiated coefficients from all models).

\section{Discussion}

We found, in a large sample of children in the general population, that CRP levels at the end of the first decade of life were associated with increases in internalising symptoms since the preschool years. This association remained robust to adjustment for the trajectory of children's externalising problems during that period and for important confounders including gender, ethnicity, SES, BMI, peer victimisation and adverse life events across childhood, but also prenatal and perinatal risk factors including maternal alcohol consumption and cigarette smoking during pregnancy, gestational diabetes or hypertension, maternal infections during pregnancy, preterm birth, low birth weight and prenatal maternal exposure to adverse life events throughout pregnancy.

We also found that the rate of increase in internalising problems was associated with IL-6, even after adjustment for our many childhood confounders. Although the level of statistical significance reduced to $\mathrm{p}=0.06$ after adjustment for the perinatal and prenatal factors we considered, the strength of association was unaltered after adjustment. Therefore, we conclude that there is evidence, albeit rather weak, that increasing internalising symptoms are associated with higher levels of IL-6 as well. Thus, our study identifies a pathway from 
chronic emotional and social problems to inflammatory markers of physical illness in childhood.

Quite why chronic emotional and social difficulties would lead to inflammation in children is not clear, but Copeland et al. (2012) whose study on adolescent depression showed similar patterns with respect to CRP has speculated as to the mechanism. According to them, depression itself may activate the stress response systems that cause it because when one is depressed one requires a lower stress activation threshold to remain depressed. Therefore, depression may be self-sustaining by producing a systemic stress response even in the absence of external stressors. The price to be paid for this constant adaptation is "wear and tear" on physiological systems, or allostatic load (McEwen and Stellar, 1993), which is evidenced by changes in physiological activity across a range of regulatory systems including the innate immune system, as evidenced by an elevation in cytokines and CRP. Arguably, both Copeland et al.'s study on adolescent depressive symptoms and ours on childhood internalising symptoms show support for this hypothesis as in both cases it was chronic symptoms that were associated with inflammation. An alternative explanation, that chronicity of symptoms would activate inflammatory responses via poor lifestyle choices (Huang et al., 2019), is less plausible here. In our sample, inflammation was measured at age 9 years, too early for the well-evidenced mechanisms, from adolescence and beyond, of smoking or drinking (although not of poor diet or physical inactivity which can be relevant since childhood) via which depression may be maintained.

Another explanation may be that the relationship is due to unobserved confounders such as social isolation which is associated with both inflammation (Smith, Gavey, Riddell, Kontari, \& Victor, 2020) and chronicity of depressive or internalising problems, particularly in late childhood and adolescence (Shovestul, Han, Germine, \& Dodell-Feder, 2020). The argument for a causal role of social isolation in inflammation is predicated on evolutionary 
theory: social isolation in humans, an extraordinarily socially-oriented species, means that physiological regulation, provided by social contact, is directly compromised. As well as via this direct path, social isolation likely has a physiological impact indirectly, because perceived social isolation (loneliness) and objective social isolation act as social stressors and activate an inflammatory response (Eisenberger, Moieni, Inagaki, Muscatell, \& Irwin, 2017). Unfortunately, we were unable to directly test this hypothesis, although we did adjust for peer victimisation in our analysis. Another possible confounder is shared genetic influence as argued by Huang et al. (2019). Our study, using observed data from a general population sample, could not assess the role of genetic factors.

It is also noteworthy that in our study the effect of chronic emotional and social symptoms was stronger on CRP than IL-6, replicating previous studies, with adults, also showing that chronic depressive symptoms prospectively predict CRP, not IL-6 (Huang et al., 2019). Huang et al. (2019) attributed their discrepant results to the different functions that each marker has in the inflammation process. Elevated IL-6 signals acute inflammatory effects with a possible direct action on the brain, whereas CRP levels may require days or weeks to rise after an inflammatory stimulus, and in fact a sustained elevation of IL-6 over time is necessary in order for circulating CRP levels to increase. Thus, IL-6 may be a better marker of the effect of acute inflammation on the brain, while CRP that of chronic, long-term inflammatory response. CRP, in contrast to IL-6, does not directly affect neurobiology, given that it does not cross the blood-brain barrier. CRP could be more directly linked to sustained behavioural and physiological consequences of depression, such as changes in body weight, diet, physical activity and sleep.

It is also important to note that we found no evidence for an association between externalising symptoms and either inflammatory marker. The research to date shows no clear link between inflammation and externalising problems in children. Cullen et al.'s (2017) 
study with 11-14 year olds showed, like ours, no association between externalising problems and CRP. Tang et al.'s (2019) longitudinal randomised trial of high-quality foster care as an alternative to institutional care showed that externalising symptom trajectories across ages 816 years were related to elevated CRP at age 16 years, although only in those who received care as usual within institution. A more recent study, however, examining the association in the general child population between internalising and externalising problems and levels of inflammatory markers (although not CRP) showed discrepant results with respect to externalising symptoms (Barbosa et al., 2020). In that cross-sectional study of 5-year-olds, tumor necrosis factor (TNF)- $\alpha$ was negatively associated with conduct problems and chemokine (C-C motif) ligand 2 (CCL2) was negatively with hyperactivity/inattention, although the association between internalising problems and IL-6 was positive, as expected.

Our longitudinal study is the first to identify robustly a pathway from chronic emotional and social problems to markers of physical illness in childhood, but it also has some important limitations. First, inflammation was only assessed once. Second, as discussed, causality cannot be inferred given the nature of our data, but results are consistent with our hypothesis. Third, the effect of the slope of internalising problems on inflammation was small. Nonetheless, we believe that our study findings have significant clinical implications (Paulus and Thompson 2019). Elevated CRP has been found to be associated with early functional and structural atherosclerotic vascular changes in children, independently of conventional risk markers (Järvisalo et al., 2002). It has been suggested that any condition that produces systemic inflammation in children, as manifested by elevated CRP, may produce endothelial dysfunction (Calderon-Garciduenas et al., 2008). The usual interpretation is that CRP is a result of the inflammation rather than part of the inflammatory process itself. If our study findings do reflect a causal relationship (Nissen et al., 2005), effective interventions to prevent or reduce chronic emotional and social difficulties in 
childhood could have health benefits in childhood and beyond. Our results are compelling enough to suggest that this may be a pathway to be tested with experimental data.

\section{Acknowledgments and Disclosures}

We are extremely grateful to all the families who took part in this study, the midwives for their help in recruiting them, and the whole ALSPAC team, including interviewers, computer and laboratory technicians, clerical workers, research scientists, statisticians, volunteers, managers, receptionists and nurses. The UK Medical Research Council and Wellcome (Grant ref: 102215/2/13/2) and the University of Bristol provide core support for ALSPAC. A comprehensive list of grants funding is available on the ALSPAC website (http://www.bristol.ac.uk/alspac/external/documents/grant-acknowledgements.pdf). This publication is the work of the authors and EF will serve as guarantor for the contents of this paper. This study was funded by the UK Economic and Social Research Council (Grant ref: ES/P001742/1). The authors report no biomedical financial interests or potential conflicts of interest. 


\section{References}

Anisman H., Ravindran A., Griffiths J., Merali Z., 1999. Endocrine and cytokine correlates of major depression and dysthymia with typical or atypical features. Mol Psychiatry, 4, 182.

Appleton A. A., Buka S. L., Mccormick M. C., Koenen K. C., Loucks E. B., Gilman S. E., Kubzansky L. D., 2011. Emotional functioning at age 7 years is associated with Creactive protein in middle adulthood. Psychosom Med, 73, 295.

Barbosa, S., Khalfallah, O., Forhan, A., Galéra, C., Heude, B., Glaichenhaus, N., Davidovic, L., 2020. Serum cytokines associated with behavior: a cross-sectional study in 5-yearold children. Brain Behav Immun.

Barnett B. E., Hanna B., Parker G., 1983. Life event scales for obstetric groups. J Psychosom Res, 27, 313-20.

Boyd A., Golding J., Macleod J., Lawlor D. A., Fraser A., Henderson J., Molloy L., Ness A., Ring S., Davey Smith G., 2013. Cohort Profile: the 'children of the 90s'--the index offspring of the Avon Longitudinal Study of Parents and Children. Int J Epidemiol, $42,111-27$.

Brook J. S., Lee J. Y., Finch S. J., Brown E. N., Brook D. W., 2013. Long-term consequences of membership in trajectory groups of delinquent behavior in an urban sample: violence, drug use, interpersonal, and neighborhood attributes. Aggress Behav, 39, 440-452.

Brown G. W., Harris T. O., Peto J., 1973. Life Events and Psychiatric-Disorders .2. Nature of Causal Link. Psychological Medicine, 3, 159-176.

Brown G. W., Sklair F., Harris T. O., Birley J. L. T., 2009. Life-events and psychiatric disorders1 Part 1: some methodological issues. Psychol Med, 3, 74. 
Calderon-Garciduenas L., Villarreal-Calderon R., Valencia-Salazar G., Henriquez-Roldan C., Gutiérrez-Castrellón P., Torres-Jardon R., Osnaya-Brizuela N., Romero L., TorresJardón R., Solt A., 2008. Systemic inflammation, endothelial dysfunction, and activation in clinically healthy children exposed to air pollutants. Inhal Toxicol, 20, 499-506.

Cole S. W., Nagaraja A. S., Lutgendorf S. K., Green P. A., Sood A. K., 2015. Sympathetic nervous system regulation of the tumour microenvironment. Nat Rev Cancer, 15, 563.

Collaboration E. R. F., 2010. C-reactive protein concentration and risk of coronary heart disease, stroke, and mortality: an individual participant meta-analysis. Lancet, 375, 132-140.

Copeland W. E., Shanahan L., Worthman C., Angold A., Costello E. J., 2012. Cumulative depression episodes predict later C-reactive protein levels: a prospective analysis. Biol Psychiatry, 71, 15-21.

Copeland W. E., Wolke D., Lereya S. T., Shanahan L., Worthman C., Costello E. J., 2014. Childhood bullying involvement predicts low-grade systemic inflammation into adulthood. Proc Natl Acad Sci, 111, 7570-7575.

Cullen, A. E., Tappin, B. M., Zunszain, P. A., Dickson, H., Roberts, R. E., Nikkheslat, N., Khondoker, M., Pariante, C. M., Fisher, H. L., Laurens, K. R., 2017. The relationship between salivary C-reactive protein and cognitive function in children aged 11-14 years: Does psychopathology have a moderating effect?. Brain Behav Immun, 66, 221-229.

Danese A., Pariante C. M., Caspi A., Taylor A., Poulton R., 2007. Childhood maltreatment predicts adult inflammation in a life-course study. Proc Natl Acad Sci, 104, 13191324. 
Danesh J., Kaptoge S., Mann A. G., Sarwar N., Wood A., Angleman S. B., Wensley F., Higgins J. P., Lennon L., Eiriksdottir G., 2008. Long-term interleukin-6 levels and subsequent risk of coronary heart disease: two new prospective studies and a systematic review. PLoS Med, 5, e78.

De Baumont A., Bortoluzzi A., De Aguiar B. W., Scotton E., Guimarães L. S. P., Kapczinski F., Da Silva C. T. B., Manfro G. G., 2019. Anxiety disorders in childhood are associated with youth IL-6 levels: a mediation study including metabolic stress and childhood traumatic events. J Psychiatr Res, 115, 43-50.

Dekker M. C., Ferdinand R. F., Van Lang N. D., Bongers I. L., Van Der Ende J., Verhulst F. C., 2007. Developmental trajectories of depressive symptoms from early childhood to late adolescence: gender differences and adult outcome. J Child Psychol Psychiatry, 48, 657-666.

Eisenberger N. I., Moieni M., Inagaki T. K., Muscatell K. A., Irwin M. R., 2017 In sickness and in health: the co-regulation of inflammation and social behavior. Neuropsychopharmacol. 42:242-253.

Fergusson D. M., John Horwood L., Ridder E. M., 2005. Show me the child at seven: the consequences of conduct problems in childhood for psychosocial functioning in adulthood. J Child Psychol Psychiatry, 46, 837-849.

Flouri E., Papachristou E., Midouhas E., Joshi H., Ploubidis G. B., Lewis G., 2018. Early adolescent outcomes of joint developmental trajectories of problem behavior and IQ in childhood. Eur Child Adolesc Psychiatry, 27, 1595-1605.

Fraser A., Macdonald-Wallis C., Tilling K., Boyd A., Golding J., Smith G. D., Henderson J., Macleod J., Molloy L., Ness A., Ring S., Nelson S. M., Lawlor D. A., 2013. Cohort Profile: The Avon Longitudinal Study of Parents and Children: ALSPAC mothers cohort. Int J Epidemiol, 42, 97-110. 
Frolkis A. D., Vallerand I. A., Shaheen A.-A., Lowerison M. W., Swain M. G., Barnabe C., Patten S. B., Kaplan G. G., 2019. Depression increases the risk of inflammatory bowel disease, which may be mitigated by the use of antidepressants in the treatment of depression. Gut, 68, 1606-1612.

Glaser R., Robles T. F., Sheridan J., Malarkey W. B., Kiecolt-Glaser J. K., 2003. Mild depressive symptoms are associated with amplified and prolonged inflammatory responses after influenza virus vaccination in older adults. Arch General Psychiatry, 60, 1009-1014.

Gluckman P. D., Hanson M. A., Cooper C.,T hornburg K. L., 2008. Effect of in utero and early-life conditions on adult health and disease. N Engl J Med, 359, 61-73.

Goodman A., Lamping D. L., Ploubidis G. B., 2010. When to Use Broader Internalising and Externalising Subscales Instead of the Hypothesised Five Subscales on the Strengths and Difficulties Questionnaire (SDQ): Data from British Parents, Teachers and Children. J Abnorm Child Psychol, 38, 1179-1191.

Goodman R., 2001. Psychometric properties of the strengths and difficulties questionnaire. J Am Acad Child Adolesc Psychiatry, 40, 1337-45.

Hammen C., 2006. Stress generation in depression: Reflections on origins, research, and future directions. J Clin Psychol, 62, 1065-1082.

Honnor M. J., Zubrick S. R., Stanley F. J., 1994. The role of life events in different categories of preterm birth in a group of women with previous poor pregnancy outcome. Eur J Epidemiol, 10, 181-8.

Huang, M., Su, S., Goldberg, J., Miller, A.H., Levantsevych, O.M., Shallenberger, L., Pimple, P., Pearce, B., Bremner, J.D., Vaccarino, V., 2019. Longitudinal association of inflammation with depressive symptoms: A 7-year cross-lagged twin difference study. Brain Behav Immun, 75, 200-207. 
JäRvisalo M. J., Harmoinen A., Hakanen M., Paakkunainen U., Viikari J., Hartiala J., LehtimäKi T., Simell O., Raitakari O. T., 2002. Elevated serum C-reactive protein levels and early arterial changes in healthy children. Arterioscler Thromb Vasc Biol, $22,1323-1328$.

Jung T., Wickrama K., 2008. An introduction to latent class growth analysis and growth mixture modeling. Soc Personal Psychol Compass, 2, 302-317.

Khandaker G. M., Pearson R. M., Zammit S., Lewis G., Jones P. B., 2014. Association of Serum Interleukin 6 and C-Reactive Protein in Childhood With Depression and Psychosis in Young Adult Life A Population-Based Longitudinal Study. JAMA Psychiatry, 71, 1121-1128.

Kiecolt-Glaser J. K., Derry H. M., Fagundes C. P., 2015. Inflammation: depression fans the flames and feasts on the heat. Am J Psychiatry, 172, 1075-1091.

Marsland A. L., Gianaros P. J., Kuan D. C.-H., Sheu L. K., Krajina K., Manuck S. B., 2015. Brain morphology links systemic inflammation to cognitive function in midlife adults. Brain Behav Immun, 48, 195-204.

Matthys W., Vanderschuren L. J., Schutter D. J., 2013. The neurobiology of oppositional defiant disorder and conduct disorder: altered functioning in three mental domains. Dev Psychopathol, 25, 193-207.

McEwen BS., Stellar, E. 1993. Stress and the individual: mechanisms leading to disease. Arch Intern Med, 153, 2093-2101.

Nissen S. E., Tuzcu E. M., Schoenhagen P., Crowe T., Sasiela W. J., Tsai J., Orazem J., Magorien R. D., O'shaughnessy C., Ganz P., 2005. Statin therapy, LDL cholesterol, C-reactive protein, and coronary artery disease. N Engl J Med, 352, 29-38.

Obradović J., Boyce W. T., 2012. Developmental psychophysiology of emotion processes. Monogr Soc Res Child Dev, 77, 120-128. 
Paulus M. P., Thompson W. K., 2019. The challenges and opportunities of small effects: the new normal in academic psychiatry. JAMA Psychiatry, 76, 353-354.

Pillinger T., D’ambrosio E., Mccutcheon R., Howes O. D., 2019. Is psychosis a multisystem disorder? A meta-review of central nervous system, immune, cardiometabolic, and endocrine alterations in first-episode psychosis and perspective on potential models. Mol Psychiatry, 24, 776-794.

Reef J., Diamantopoulou S., Van Meurs I., Verhulst F. C., Van Der Ende J., 2011. Developmental trajectories of child to adolescent externalizing behavior and adult DSM-IV disorder: results of a 24-year longitudinal study. Soc Psychiatry Psychiatr Epidemiol, 46, 1233-1241.

Rutter M., Kim-Cohen J., Maughan B., 2006. Continuities and discontinuities in psychopathology between childhood and adult life. J Child Psychol Psychiatry, 47, 276-295.

Shields G. S., Moons W. G., Slavich G. M., 2017. Inflammation, self-regulation, and health: An immunologic model of self-regulatory failure. Perspect Psychol Sci, 12, 588-612.

Shovestul, B., Han, J., Germine, L., Dodell-Feder, D. 2020. Risk factors for loneliness: The high relative importance of age versus other factors. PloS one, 15, e0229087.

Slopen N., Kubzansky L. D., Koenen K. C., 2013a. Internalizing and externalizing behaviors predict elevated inflammatory markers in childhood. Psychoneuroendocrinology, 38, 2854-2862.

Slopen N., Kubzansky L. D., Mclaughlin K. A., Koenen K. C., 2013b. Childhood adversity and inflammatory processes in youth: a prospective study. Psychoneuroendocrinology, 38, 188-200.

Slopen N., Loucks E. B., Appleton A. A., Kawachi I., Kubzansky L. D., Non A. L., Buka S.,Gilman S. E., 2015. Early origins of inflammation: An examination of prenatal and 
childhood social adversity in a prospective cohort study. Psychoneuroendocrinology, $51,403-413$.

Smith K. J., Gavey, S., Riddell, N. E., Kontari, P., Victor, C. 2020. The association between loneliness, social isolation and inflammation: A systematic review and meta-analysis. Neurosci Biobehav Rev. 112, 519-541

Stewart J. C., Rand K. L., Muldoon M. F., Kamarck T. W., 2009. A prospective evaluation of the directionality of the depression-inflammation relationship. Brain Behav Immun, 23, 936-944.

Tang A., Fox N. A., Nelson C. A., Zeanah C. H., Slopen N., 2019. Externalizing trajectories predict elevated inflammation among adolescents exposed to early institutional rearing: A randomized clinical trial. Psychoneuroendocrinology, 109, 104408.

Winsper C., Lereya T., Zanarini M., Wolke D., 2012. Involvement in bullying and suiciderelated behavior at 11 years: a prospective birth cohort study. J Am Acad Child Adolesc Psychiatry, 51, 271-282. e3.

Wolkowitz O. M., Mellon S. H., Epel E. S., Lin J., Dhabhar F. S., Su Y., Reus V. I., Rosser R., Burke H. M., Kupferman E., 2011. Leukocyte telomere length in major depression: correlations with chronicity, inflammation and oxidative stresspreliminary findings. PloS one, 6, e17837.

Woods S.,Wolke D., 2003. Does the content of anti-bullying policies inform us about the prevalence of direct and relational bullying behaviour in primary schools? Educ Psychol, 23, 381-401. 


\begin{tabular}{|c|c|c|c|c|}
\hline \multicolumn{5}{|c|}{ Continuous variables } \\
\hline & $\mathbf{N}$ & \multicolumn{3}{|c|}{$\mathbf{M}(\mathbf{S D})$} \\
\hline Internalising symptoms, 4 years & 3,781 & \multicolumn{3}{|c|}{$2.85(2.34)$} \\
\hline Internalising symptoms, 6 years & 3,650 & \multicolumn{3}{|c|}{$2.43(2.43)$} \\
\hline Internalising symptoms, 8 years & 3,627 & \multicolumn{3}{|c|}{$2.79(2.64)$} \\
\hline Internalising symptoms, 9 years & 3,877 & \multicolumn{3}{|c|}{$2.46(2.61)$} \\
\hline Externalising symptoms, 4 years & 3,767 & \multicolumn{3}{|c|}{$5.77(3.22)$} \\
\hline Externalising symptoms, 6 years & 3,641 & \multicolumn{3}{|c|}{$4.80(3.25)$} \\
\hline Externalising symptoms, 8 years & 3,627 & \multicolumn{3}{|c|}{$4.64(3.38)$} \\
\hline Externalising symptoms, 9 years & 3,876 & \multicolumn{3}{|c|}{$4.09(3.12)$} \\
\hline Body mass index, 9 years & 4,474 & \multicolumn{3}{|c|}{$17.58(2.76)$} \\
\hline Prenatal adverse life events & 3,944 & \multicolumn{3}{|c|}{$5.58(2.94)$} \\
\hline Adverse life events, 18 months & 4,050 & \multicolumn{3}{|c|}{$0.91(1.08)$} \\
\hline Adverse life events, 30 months & 3,867 & \multicolumn{3}{|c|}{$1.33(1.25)$} \\
\hline Adverse life events, 42 months & 3,885 & \multicolumn{3}{|c|}{$1.56(1.22)$} \\
\hline Adverse life events, 57 months & 3,811 & \multicolumn{3}{|c|}{$1.77(1.10)$} \\
\hline Adverse life events, 69 months & 3,666 & \multicolumn{3}{|c|}{$1.31(1.16)$} \\
\hline Adverse life events, 81 months & 3,867 & \multicolumn{3}{|c|}{$1.24(1.11)$} \\
\hline Adverse life events, 103 months & 3,776 & \multicolumn{3}{|c|}{$1.12(1.13)$} \\
\hline Inflammatory markers & & Median & M (SD) & IQR \\
\hline Interleukin $6(\mathrm{pg} / \mathrm{mL})$ & 4,525 & 0.77 & $1.21(1.47)$ & 0.87 \\
\hline C-reactive protein (mg/L) & 4,525 & 0.20 & $0.62(1.93)$ & 0.37 \\
\hline \multicolumn{5}{|c|}{ Categorical variables } \\
\hline & $\mathbf{N}$ & \multicolumn{3}{|c|}{$\%$} \\
\hline Maternal education: Certificate of Secondary Education & 409 & \multicolumn{3}{|c|}{10.17} \\
\hline Maternal education: Vocational qualification & 325 & \multicolumn{3}{|c|}{8.08} \\
\hline Maternal education: Ordinary level & 1,464 & \multicolumn{3}{|c|}{36.40} \\
\hline Maternal education: Advanced level & 1,121 & \multicolumn{3}{|c|}{27.87} \\
\hline Maternal education: University degree & 703 & \multicolumn{3}{|c|}{17.48} \\
\hline Smoking during pregnancy & 1,302 & \multicolumn{3}{|c|}{28.77} \\
\hline Alcohol use during pregnancy & 3,009 & \multicolumn{3}{|c|}{67.06} \\
\hline Hypertension or diabetes during pregnancy & 227 & \multicolumn{3}{|c|}{8.66} \\
\hline Infections during pregnancy & 1,624 & \multicolumn{3}{|c|}{40.87} \\
\hline Normal birth weight ( $>2,500$ grams) & 4,342 & & 95.96 & \\
\hline
\end{tabular}




\begin{tabular}{|l|c|c|}
\hline Full-term delivery & 2,456 & 92.64 \\
\hline Pure victim, 8 years & 1,282 & 34.40 \\
\hline Pure bully, 8 years & 64 & 1.73 \\
\hline Bully-victim, 8 years & 244 & 6.58 \\
\hline Not involved in bullying, 8 years & 3,335 & 89.22 \\
\hline Female & 2,225 & 49.21 \\
\hline Non-white & 167 & 4.07 \\
\hline Note: M=Mean; SD=Standard Deviation; IQR=Interquartile Range \\
\hline
\end{tabular}


Table 2. Regression coefficients for log IL-6 and log CRP according to slopes and intercepts of internalising and externalising symptoms

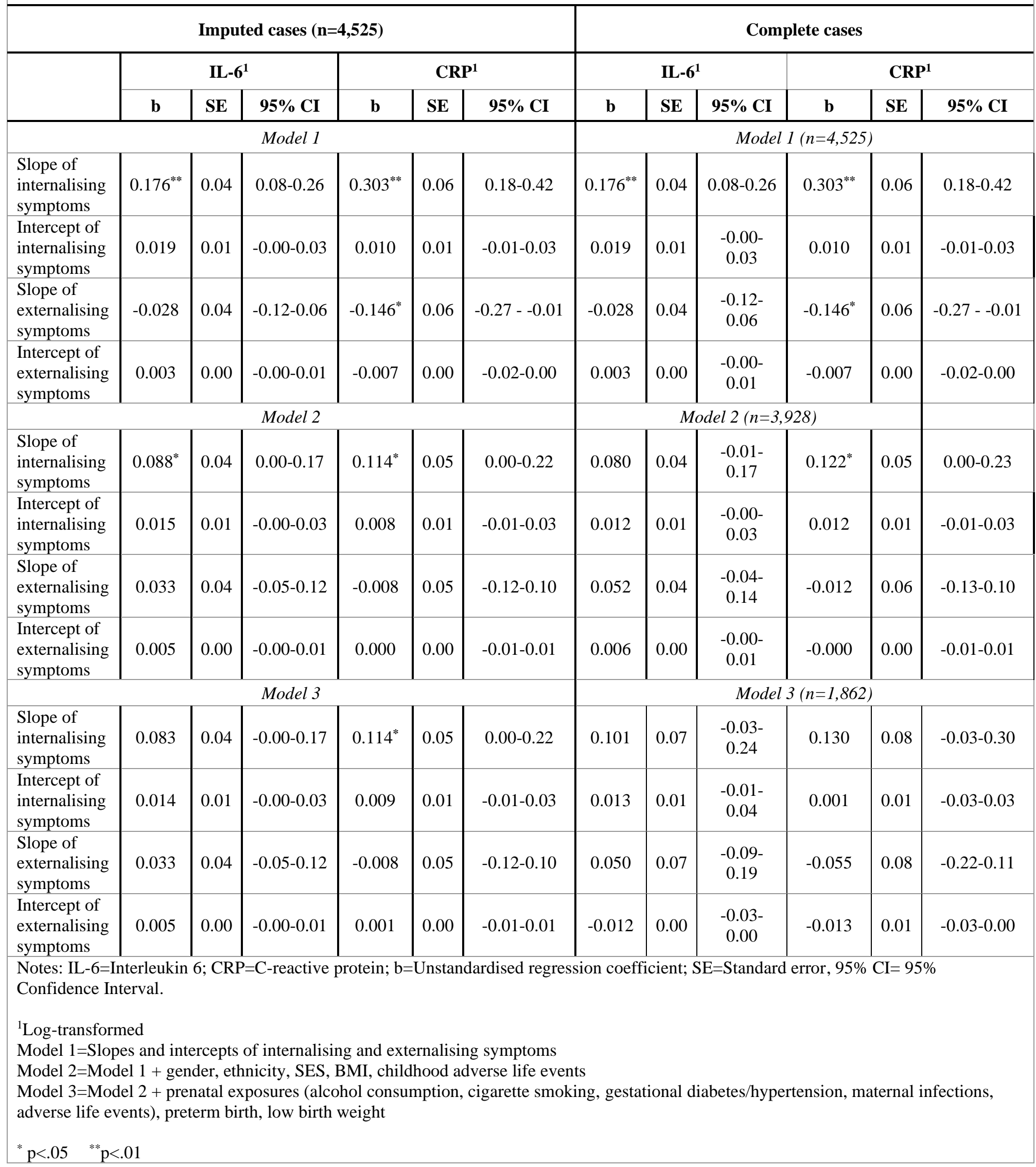




\section{Appendix}

Sensitivity Analysis

In our analytic sample $(n=4,525)$ we found that the increase of internalising symptoms from ages 4 to 9 years was associated with higher levels inflammatory markers at age 9 even after full adjustment for confounders. We carried out a sensitivity analysis to test if our results hold if we exclude children with a psychiatric disorder from the sample. In ALSPAC, psychiatric disorders were assessed at ages 7 and 10 years using the parent version of the Development and Well-Being Assessment (DAWBA) and were coded according to DSM-IV criteria by two experienced psychiatrists. The DAWBA assesses the presence of emotional, behavioural, and hyperactivity disorders in children. The main exposure of our study was the growth of internalising symptoms. Internalising symptoms include anxiety symptoms, somatic complaints, or withdrawal. Therefore, for our sensitivity analysis we excluded children with any emotional disorder diagnosis $(n=141)$ and refitted our models. Results did not change in this smaller sample of 4,384 children with no emotional disorders. 


\begin{tabular}{|c|c|c|}
\hline \multicolumn{3}{|c|}{ Table S1. List of prenatal $(n=41)$ and childhood $(n=14)$ events } \\
\hline \multicolumn{2}{|c|}{ Prenatal events } & \multirow{2}{*}{$\begin{array}{r}\text { Childhood events } \\
\text { Child was taken into care }\end{array}$} \\
\hline Your husband/partner died & One of your children died & \\
\hline A friend or relative died & One of your children was ill & A pet died \\
\hline Your husband or partner was ill & A friend or relative was ill & Child moved home \\
\hline You were admitted to hospital & You were in trouble with the law & Child had a shock or fright \\
\hline You were divorced & $\begin{array}{l}\text { You found that your } \\
\text { husband/partner didn't want your } \\
\text { child }\end{array}$ & $\begin{array}{l}\text { Child was physically hurt by } \\
\text { someone }\end{array}$ \\
\hline You were very ill & Your husband/partner lost his job & Child was sexually abused \\
\hline $\begin{array}{l}\text { Your husband/partner had } \\
\text { problems at work }\end{array}$ & You had problems at work & $\begin{array}{l}\text { Child was separated from } \\
\text { mother for at least a week }\end{array}$ \\
\hline You lost your job & Your husband/partner went away & $\begin{array}{l}\text { Child was separated from } \\
\text { father for at least a week }\end{array}$ \\
\hline $\begin{array}{l}\text { Your husband/partner was in } \\
\text { trouble with the law }\end{array}$ & $\begin{array}{l}\text { You and your husband/ partner } \\
\text { separated }\end{array}$ & Child acquired a new parent \\
\hline Your income was reduced & $\begin{array}{l}\text { You argued with your } \\
\text { husband/partner }\end{array}$ & $\begin{array}{l}\text { Child had a new brother or } \\
\text { sister }\end{array}$ \\
\hline $\begin{array}{l}\text { You argued with your family and } \\
\text { friends }\end{array}$ & You moved house & Child was admitted to hospital \\
\hline Your partner hurt you physically & You became homeless & Child changed carer/caregiver \\
\hline You had a major financial problem & You got married & $\begin{array}{l}\text { Child was separated from } \\
\text { someone else }\end{array}$ \\
\hline $\begin{array}{l}\text { Your husband/partner was } \\
\text { physically cruel to your children }\end{array}$ & You attempted suicide & $\begin{array}{l}\text { Child started/changed } \\
\text { crèche/nursery/school }\end{array}$ \\
\hline You were convicted of an offence & $\begin{array}{l}\text { You were bleeding and thought } \\
\text { you might miscarry }\end{array}$ & \\
\hline You started a new job & $\begin{array}{l}\text { You had a test to see if your baby } \\
\text { was abnormal }\end{array}$ & \\
\hline $\begin{array}{l}\text { You had a result on a test that } \\
\text { suggested your baby might not be } \\
\text { normal }\end{array}$ & $\begin{array}{l}\text { You were told that you were going } \\
\text { to have twins }\end{array}$ & \\
\hline $\begin{array}{l}\text { You heard that something that had } \\
\text { happened might be harmful to the } \\
\text { baby }\end{array}$ & You tried to have an abortion & \\
\hline You took an examination & $\begin{array}{l}\text { Your husband/partner was } \\
\text { emotionally cruel to you }\end{array}$ & \\
\hline $\begin{array}{l}\text { Your husband/partner was } \\
\text { emotionally cruel to your children }\end{array}$ & Your house or car was burgled & \\
\hline You had an accident & & \\
\hline
\end{tabular}


Table S2. Pearson's correlations of the main study variables in the analytic sample $(n=4,525)$

\begin{tabular}{|c|c|c|c|c|c|c|c|c|c|c|}
\hline & $\begin{array}{l}\text { Internalising } \\
\text { symptoms, } \\
\text { age } 4\end{array}$ & $\begin{array}{l}\text { Internalising } \\
\text { symptoms, } \\
\text { age } 6\end{array}$ & $\begin{array}{l}\text { Internalising } \\
\text { symptoms, } \\
\text { age } 8\end{array}$ & $\begin{array}{l}\text { Internalising } \\
\text { symptoms, } \\
\text { age } 9\end{array}$ & $\begin{array}{l}\text { Externalising } \\
\text { symptoms, } \\
\text { age } 4\end{array}$ & $\begin{array}{l}\text { Externalising } \\
\text { symptoms, } \\
\text { age } 6\end{array}$ & $\begin{array}{l}\text { Externalising } \\
\text { symptoms, } \\
\text { age } 8\end{array}$ & $\begin{array}{l}\text { Externalising } \\
\text { symptoms, } \\
\text { age } 9\end{array}$ & $\begin{array}{l}\text { IL-6, } \\
\text { age } 9\end{array}$ & $\begin{array}{l}\text { CRP } \\
\text { age } 9\end{array}$ \\
\hline $\begin{array}{l}\text { Internalising } \\
\text { symptoms, } \\
\text { age } 4\end{array}$ & 1 & & & & & & & & & \\
\hline $\begin{array}{l}\text { Internalising } \\
\text { symptoms, } \\
\text { age } 6\end{array}$ & $0.46^{* *}$ & 1 & & & & & & & & \\
\hline $\begin{array}{l}\text { Internalising } \\
\text { symptoms, } \\
\text { age } 8\end{array}$ & $0.42^{* * *}$ & $0.62^{* * *}$ & 1 & & & & & & & \\
\hline $\begin{array}{l}\text { Internalising } \\
\text { symptoms, } \\
\text { age } 9\end{array}$ & $0.37^{\text {** }}$ & $0.56^{* *}$ & $0.61^{* *}$ & 1 & & & & & & \\
\hline $\begin{array}{l}\text { Externalising } \\
\text { symptoms, } \\
\text { age } 4\end{array}$ & $0.28^{* * *}$ & $0.20^{* * *}$ & $0.22^{* * *}$ & $0.19^{* * *}$ & 1 & & & & & \\
\hline $\begin{array}{l}\text { Externalising } \\
\text { symptoms, } \\
\text { age } 6\end{array}$ & $0.20^{* * *}$ & $0.36^{* *}$ & $0.31^{* *}$ & $0.29^{* *}$ & $0.59^{* *}$ & 1 & & & & \\
\hline
\end{tabular}




\begin{tabular}{|c|c|c|c|c|c|c|c|c|c|c|}
\hline $\begin{array}{l}\text { Externalising } \\
\text { symptoms, } \\
\text { age } 8\end{array}$ & $0.22^{* *}$ & $0.28^{* *}$ & $0.36^{* *}$ & $0.29^{* *}$ & $0.57^{* *}$ & $0.73^{* *}$ & 1 & & & \\
\hline $\begin{array}{l}\text { Externalising } \\
\text { symptoms, } \\
\text { age } 9\end{array}$ & $0.19^{* *}$ & $0.28^{* *}$ & $0.30^{* *}$ & $0.37^{* *}$ & $0.53^{* *}$ & $0.70^{* *}$ & $0.74^{* *}$ & 1 & & \\
\hline $\begin{array}{l}\text { IL-6, } \\
\text { age } 9\end{array}$ & 0.00 & 0.01 & $0.04^{* *}$ & $0.04^{* *}$ & 0.01 & 0.01 & 0.02 & 0.02 & 1 & \\
\hline $\begin{array}{l}\text { CRP, } \\
\text { age } 9\end{array}$ & -0.00 & 0.01 & $0.05^{* *}$ & $0.07^{* *}$ & 0.00 & 0.01 & 0.00 & 0.01 & $0.40^{* *}$ & 1 \\
\hline $\begin{array}{l}\text { BMI, } \\
\text { age } 9\end{array}$ & -0.01 & -0.00 & $0.03^{*}$ & $0.06^{* *}$ & 0.03 & $0.03^{*}$ & $0.03^{*}$ & 0.00 & $0.12^{\text {** }}$ & $0.20^{* * *}$ \\
\hline $\begin{array}{l}\text { Maternal } \\
\text { education }\end{array}$ & $-0.09^{* *}$ & $-0.06^{* *}$ & $-0.03^{*}$ & $-0.06^{* *}$ & $-0.17^{* *}$ & $-0.13^{* *}$ & $-0.11^{* *}$ & $-0.12^{* *}$ & -0.02 & $-0.04^{*}$ \\
\hline $\begin{array}{l}\text { Prenatal } \\
\text { ALE }\end{array}$ & $0.08^{* *}$ & $0.14^{* *}$ & $0.13^{* *}$ & $0.12^{* *}$ & $0.12^{* *}$ & $0.13^{* *}$ & $0.13^{* *}$ & $0.13^{* * *}$ & 0.01 & -0.00 \\
\hline $\begin{array}{l}\text { Childhood } \\
\text { ALE } \\
18 \text { months }\end{array}$ & $0.05^{\text {** }}$ & $0.08^{* *}$ & $0.07^{* *}$ & $0.06^{* *}$ & $0.08^{* *}$ & $0.08^{* * *}$ & $0.09^{* * *}$ & $0.09^{* * *}$ & 0.00 & -0.02 \\
\hline $\begin{array}{l}\text { Childhood } \\
\text { ALE } \\
30 \text { months }\end{array}$ & $0.06^{* *}$ & $0.07^{* *}$ & $0.06^{* *}$ & $0.04^{* *}$ & $0.06^{* *}$ & $0.09^{* *}$ & $0.07^{* *}$ & $0.08^{* * *}$ & -0.00 & 0.00 \\
\hline $\begin{array}{l}\text { Childhood } \\
\text { ALE }\end{array}$ & $0.08^{* *}$ & $0.07^{* *}$ & $0.09^{* *}$ & $0.07^{* *}$ & $0.06^{* *}$ & $0.05^{* *}$ & $0.05^{\text {** }}$ & $0.05^{* *}$ & 0.00 & -0.00 \\
\hline
\end{tabular}




\begin{tabular}{|c|c|c|c|c|c|c|c|c|c|c|}
\hline 42 months & & & & & & & & & & \\
\hline $\begin{array}{l}\text { Childhood } \\
\text { ALE } \\
57 \text { months }\end{array}$ & $0.08^{* k}$ & $0.09^{* * *}$ & $0.08^{* *}$ & $0.09^{* *}$ & $0.05^{* *}$ & $0.07^{\text {*k* }}$ & $0.07^{* * *}$ & $0.07^{* * *}$ & 0.00 & 0.02 \\
\hline $\begin{array}{l}\text { Childhood } \\
\text { ALE } \\
69 \text { months }\end{array}$ & $0.04^{*}$ & $0.09^{* * *}$ & $0.09^{* *}$ & $0.06^{* *}$ & $0.05^{\text {** }}$ & $0.07^{* *}$ & $0.09^{* * *}$ & $0.05^{* *}$ & 0.01 & 0.02 \\
\hline $\begin{array}{l}\text { Childhood } \\
\text { ALE } \\
81 \text { months }\end{array}$ & 0.03 & $0.10^{* * *}$ & $0.11^{\text {*** }}$ & $0.10^{* *}$ & $0.06^{* *}$ & $0.09^{* *}$ & $0.09^{* * *}$ & $0.07^{* * *}$ & $0.03^{*}$ & $0.05^{* *}$ \\
\hline $\begin{array}{l}\text { Childhood } \\
\text { ALE } \\
103 \text { months }\end{array}$ & $0.05^{* *}$ & $0.05^{* *}$ & $0.07^{* *}$ & $0.05^{* *}$ & $0.05^{* *}$ & $0.06^{* *}$ & $0.07^{* * *}$ & $0.09^{* * *}$ & $0.03^{*}$ & 0.00 \\
\hline $\begin{array}{l}\text { Pure bully, } \\
\text { age } 8\end{array}$ & 0.02 & 0.03 & 0.02 & 0.03 & $0.04^{* *}$ & $0.04^{*}$ & $0.05^{* * *}$ & $0.05^{\text {** }}$ & -0.01 & -0.00 \\
\hline $\begin{array}{l}\text { Pure victim, } \\
\text { age } 8\end{array}$ & 0.02 & $0.08^{* *}$ & $0.10^{* *}$ & $0.13^{* *}$ & $0.06^{* *}$ & $0.12^{* *}$ & $0.09^{* *}$ & $0.12^{* *}$ & 0.03 & $0.03^{*}$ \\
\hline $\begin{array}{l}\text { Bully-victim, } \\
\text { age } 8\end{array}$ & 0.01 & 0.02 & $0.05^{* *}$ & $0.04^{* *}$ & $0.09^{* *}$ & $0.12^{* * *}$ & $0.11^{* *}$ & $0.13^{\text {** }}$ & -0.01 & -0.01 \\
\hline $\begin{array}{l}\text { Not involved } \\
\text { in bullying, } \\
\text { age } 8\end{array}$ & -0.00 & $-0.06^{* * *}$ & $-0.07^{* *}$ & $-0.09^{* *}$ & $-0.07^{\text {*** }}$ & $-0.10^{* * *}$ & $-0.08^{* * *}$ & $-0.10^{* * *}$ & -0.00 & $-0.03^{*}$ \\
\hline $\begin{array}{l}\text { Alcohol use } \\
\text { in pregnancy }\end{array}$ & 0.00 & 0.00 & $0.04^{* *}$ & 0.02 & $0.03^{*}$ & 0.02 & $0.05^{* * *}$ & $0.04^{*}$ & 0.00 & 0.00 \\
\hline
\end{tabular}




\begin{tabular}{|c|c|c|c|c|c|c|c|c|c|c|}
\hline $\begin{array}{l}\text { Smoking in } \\
\text { pregnancy }\end{array}$ & $0.09^{* * *}$ & $0.06^{* *}$ & $0.07^{* *}$ & $0.08^{* *}$ & $0.10^{* *}$ & $0.11^{* *}$ & $0.09^{* *}$ & $0.10^{* * *}$ & $0.03^{*}$ & 0.02 \\
\hline $\begin{array}{l}\text { Hypertensio } \\
\text { n/diabetes in } \\
\text { pregnancy }\end{array}$ & 0.01 & 0.03 & 0.03 & 0.01 & -0.03 & 0.00 & -0.01 & -0.00 & 0.01 & 0.00 \\
\hline $\begin{array}{l}\text { Infections in } \\
\text { pregnancy }\end{array}$ & -0.00 & 0.03 & 0.02 & $0.03^{* *}$ & $0.04^{* *}$ & 0.04 & $0.05^{* *}$ & $0.05^{* *}$ & $0.06^{* *}$ & 0.00 \\
\hline Female & -0.00 & 0.00 & 0.02 & $0.04^{* * *}$ & $-0.08^{* *}$ & $-0.12^{* *}$ & $-0.14^{* *}$ & $-0.13^{* *}$ & -0.00 & $0.05^{* *}$ \\
\hline $\begin{array}{l}\text { Normal birth } \\
\text { weight }\end{array}$ & -0.01 & $-0.03^{*}$ & -0.03 & -0.00 & -0.00 & -0.01 & -0.01 & -0.01 & -0.01 & 0.01 \\
\hline $\begin{array}{l}\text { Full-term } \\
\text { delivery }\end{array}$ & 0.00 & -0.00 & -0.02 & 0.00 & -0.00 & -0.00 & -0.01 & -0.01 & 0.02 & 0.01 \\
\hline Non-white & 0.01 & 0.03 & 0.02 & 0.01 & 0.02 & 0.01 & 0.02 & 0.02 & 0.02 & -0.01 \\
\hline $\begin{array}{l}\text { Note: IL-6=Int } \\
{ }^{*} \mathrm{p}<.05 \quad{ }^{* *} \mathrm{p} \\
\end{array}$ & ukin & & & & & & & & & \\
\hline
\end{tabular}


Table S3. Exponentiated regression coefficients for log IL-6 and log CRP according to slopes and intercepts of internalising and externalising symptoms

\begin{tabular}{|c|c|c|c|c|}
\hline \multicolumn{3}{|c|}{ Imputed cases $(n=4,525)$} & \multicolumn{2}{|c|}{ Complete cases } \\
\hline & IL-6 $^{1}$ & CRP $^{1}$ & IL-6 $^{1}$ & CRP' $^{1}$ \\
\hline & b & b & b & b \\
\hline \multicolumn{3}{|c|}{ Model 1} & \multicolumn{2}{|c|}{ Model $1(n=4,525)$} \\
\hline $\begin{array}{l}\text { Slope of } \\
\text { internalising } \\
\text { symptoms }\end{array}$ & 1.18 & 1.34 & 1.18 & 1.34 \\
\hline $\begin{array}{l}\text { Intercept of } \\
\text { internalising } \\
\text { symptoms }\end{array}$ & 1.01 & 1.01 & 1.01 & 1.01 \\
\hline $\begin{array}{l}\text { Slope of } \\
\text { externalising } \\
\text { symptoms }\end{array}$ & 0.98 & 0.86 & 0.98 & 0.86 \\
\hline $\begin{array}{l}\text { Intercept of } \\
\text { externalising } \\
\text { symptoms }\end{array}$ & 1 & 1 & 1 & 1 \\
\hline \multicolumn{3}{|c|}{ Model 2} & \multicolumn{2}{|c|}{ Model $2(n=3,928)$} \\
\hline $\begin{array}{l}\text { Slope of } \\
\text { internalising } \\
\text { symptoms }\end{array}$ & 1.08 & 1.11 & 1.08 & 1.12 \\
\hline $\begin{array}{l}\text { Intercept of } \\
\text { internalising } \\
\text { symptoms }\end{array}$ & 1.01 & 1 & 1.01 & 1.01 \\
\hline $\begin{array}{l}\text { Slope of } \\
\text { externalising } \\
\text { symptoms }\end{array}$ & 1.03 & 1 & 1.05 & 0.99 \\
\hline $\begin{array}{l}\text { Intercept of } \\
\text { externalising } \\
\text { symptoms }\end{array}$ & 1 & 1 & 1 & 1 \\
\hline \multicolumn{3}{|c|}{ Model 3} & \multicolumn{2}{|c|}{ Model $3(n=1,862)$} \\
\hline $\begin{array}{l}\text { Slope of } \\
\text { internalising } \\
\text { symptoms }\end{array}$ & 1.08 & 1.11 & 1.10 & 1.13 \\
\hline $\begin{array}{l}\text { Intercept of } \\
\text { internalising } \\
\text { symptoms }\end{array}$ & 1.01 & 1 & 1.01 & 1 \\
\hline $\begin{array}{l}\text { Slope of } \\
\text { externalising } \\
\text { symptoms }\end{array}$ & 1.03 & 1 & 1.05 & 0.95 \\
\hline
\end{tabular}




\begin{tabular}{|l|l|l|l|l|}
\hline $\begin{array}{l}\text { Intercept of } \\
\text { externalising } \\
\text { symptoms }\end{array}$ & 1 & 1 & 0.99 & 0.99 \\
\hline
\end{tabular}

Notes: IL-6=Interleukin 6; CRP=C-reactive protein.

\section{${ }^{1}$ Log-transformed}

Model 1=Slopes and intercepts of internalising and externalising symptoms

Model 2=Model 1 + gender, ethnicity, SES, BMI, childhood adverse life events

Model 3=Model 2 + prenatal exposures (alcohol consumption, cigarette smoking, gestational diabetes/hypertension, maternal infections, adverse life events), preterm birth, low birth weight

${ }^{*} \mathbf{p}<.05 \quad{ }^{* *} p<.01$ 
